\title{
INCREASING PRIMARY CONTAINMENT CAPABILITIES OF LIQUID-METAL FAST BREEDER REACTOR PLANTS BY THE USE OF PRESTRESSED CONCRETE
}

\author{
RALPH W. SEIDENSTICKER and ALGIRDAS H. MARCHERTAS \\ Argonne National Laboratory, Engineering Mechanics Program \\ Reactor Analysis and Safety Division, Argonne, Illinois 60439
}

ZDENĚK P. BAŽANT Northwestern University

Evanston, Illinois 60201

Received January 28, 1980

Accepted for Publication May 22, 1980

The Argonne National Laboratory developed computer program DYNAPCON for the transient analysis of a prestressed concrete reactor vessel (PCRV) for liquid-metal fast breeder reactor (LMFBR) primary containment is applied to a reference design concept representative of large, pool-type LMFBR reactor plants. Estimates of the energy absorption capability of a PCRV primary containment vessel are provided to assist in the establishment of the engineering feasibility of such a design concept.

The reference design analyzed utilizes existing concrete structures already in place for biological shielding and component support. The very large energy absorption capability is achieved through the use of fairly large amounts of prestressing steel and mild steel reinforcement within these concrete matrices.

Energy sources used range from 2720 to 10880 $M W$-s. Even for the largest energy source, the maximum computed strain in the prestressing tendon anywhere in the structure is $\sim 2.3 \%$, which is still below the strain associated with the minimum ultimate stress levels for most prestressing steels. These results are very encouraging and should provide sufficient incentive to more firmly establish the feasibility of this concept of using a PCR V for primary containment.

\section{INTRODUCTION}

Marchertas and Belytschko ${ }^{1}$ have described the development of a computer program for use in analyzing the behavior of a prestressed concrete reactor vessel (PCRV) under transient loading conditions. The purpose of this paper is to describe the results of applying that computer program to a full-sized liquid-metal fast breeder reactor (LMFBR) plant to obtain an estimate of the energy absorption capability of the primary containment of that plant in resisting the effects of a large, hypothetical core disruptive accident (HCDA). Such estimates are of value in establishing the feasibility of using a PCRV for LMFBR primary containment. Ultimately, feasibility of a PCRV for such use rests on the basis that it provides much greater energy absorption than steel reactor vessels currently in use, and that it can economically provide sufficient capability for absorbing the effects of even the most severe HCDA scenarios considered. Although work is still under way, preliminary results reported in this paper are, indeed, very encouraging.

\section{DESCRIPTION OF PRIMARY CONTAINMENT DESIGN}

The configuration used for the PCRV in this application study was chosen to closely resemble (physically) the basic structure used for biological shielding in typical pool-type LMFBR plants. The purpose of this was to see if sufficiently large increases in energy absorption capability could be 
obtained by merely prestressing and reinforcing the concrete aiready needed for radiation shielding and support of components. Then, if the energy absorption capability is sufficiently large, we can state that use of the PCRV will probably have a negligible effect on the overall size of the secondary containment structure.

The PCRV design configuration selected is shown in Fig. 1. Essential dimensions, such as inside diameter, overall height, top closure head thickness, and radial biological shield wall thickness, were chosen to be fairly representative of large, pool-type LMFBR plants, such as the French Super-Phenix and recent U.S. designs resulting from an Electric Power Research Institute sponsored program for pool-type LMFBR design studies. The design of both the prestressing steel system and mild steel reinforcement was based primarily on obtaining as much steel as practical within the physical limitations of the concrete vessel. The amount of steel is by no means optimal; additional work is under way and changes in the amount shown are likely. It is expected, however, that such changes will tend to reduce the amount of steel and, perhaps, some redistribution of the prestressing tendons.

The basic philosophy employed in selecting both the prestressing steel and the mild steel reinforcing was as follows:

1. Use as much mild steel reinforcement as practical in addition to prestressing steel. Actually, for the present design, there is much more mild steel than prestressing steel. The percentage of mild steel to concrete used in the current design is $4 \%$, in both the vertical and horizontal (hoop) directions.

2. Use a smaller value for the stress level in the prestressing steel than normally used in the design of prestressed concrete containment vessels. The design analyzed in this paper uses an effective (net) prestress level of $50 \%$ of the ultimate strength of the prestressing steel versus the value of $70 \%$ minus prestress losses normally used. The benefit of this reduction is to permit the prestressing steel to absorb more energy in its elastic range of behavior.

3. Use heavy cross-wall mild steel ties that should greatly reduce the cracking of concrete. The percentage of cross-wall steel ties used in this analysis was $2.77 \%$. This is desired to assure that the concrete undergoes a three-dimensional confining pressure that tends to increase its ductility, delay crack formation, and increase the absorption of the energy.

4. Additional strength could still be derived, if necessary, by (a) increasing the percentage of mild steel reinforcement to, say, $6 \%$, and (b) reducing the effective prestress level to $\sim 30 \%$ of the ultimate strength of the prestressing steel (the structure might then be called the "partially prestressed" concrete vessel).

As shown in Fig. 1, a separate steel vessel (or tank) carrying the primary sodium is suspended from the top closure head, and a gas gap of $\sim 0.3 \mathrm{~m}$ exists between this steel vessel and the inner surface of the PCRV. First of all, it should be noted that no energy is assumed to be absorbed by this suspended steel vessel keeping the calculations on the safe side. For the greatly simplified design shown here, the steel vessel merely acts to establish a barrier for the liquid sodium. Further work is required to establish more realistic design configurations, including the use of some type of insulation on the inner liner of the PCRV.

\section{DESCRIPTION OF ANALYTICAL MODEL AND APPROACH}

The analytical modeling of the PCRV response was done by means of two codes, ICECO (Ref. 2) and DYNAPCON (Ref. 3). The HCDA reactor core expansion was modeled by the hydrodynamics code ICECO, providing the internal pressure loading on the inside walls of the PCRV model. The analytical ICECO model involved simplifying geometry assumptions that influenced the pressure history results. First, the outside boundaries (PCRV walls) were taken to be ideally rigid. This is considered to be a good assumption in view of the facts that the true PCRV displacements are really quite small and that no gas space is considered in calculations between the steel vessel and the PCRV wall. Neglecting the gas space may be overly conservative, since it could account for a significant reduction of pressure on the walls of the PCRV.

Furthermore, the core support structure and the core barrel are taken as being completely rigid. The assumption of a rigid core support structure seems reasonable, taking into consideration the large mass of the structure and the relatively short time of core expansion. The rigid-core-barrel assumption was made with the intention of simplifying the analytical solution and also yielding a conservative loading on the PCRV due to slug impact of sodium on the top slab. The error caused by this assumption is small for the reference HCDA case, but could become appreciable for the larger energy cases. Future work will include the use of a flexible core barrel to assess its effects on magnitude and location of maximum strains in the prestressing steel.

For computations, the analytical ICECO model was assumed to have a flat bottom. This is a departure from the design shown in Fig. 1 and was done to simplify the ICECO modeling. This modification should not greatly affect the results of the ICECO load predictions, especially as far as the loading on 

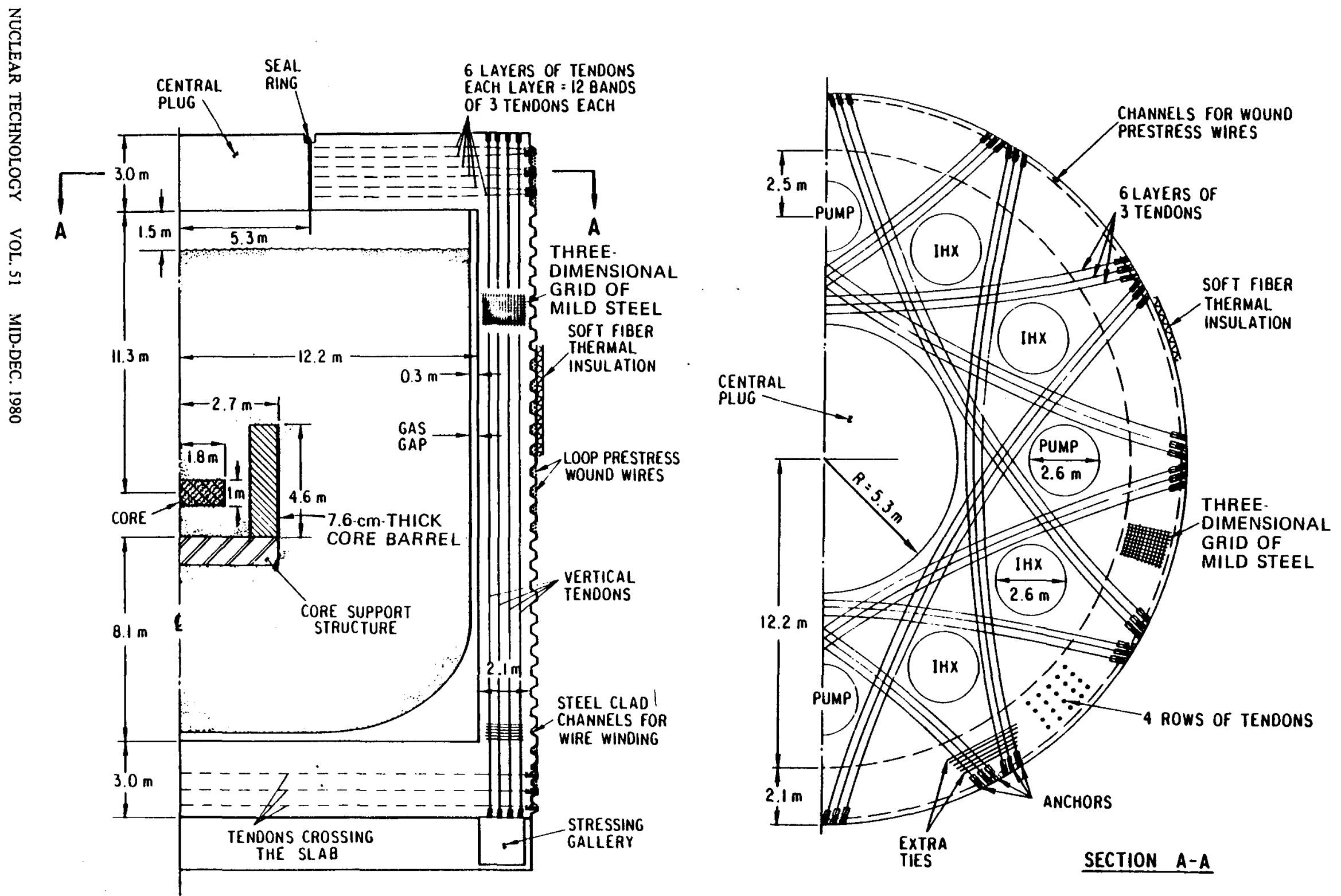

Fig. 1. Reinforcement and prestressing details of the biological shielding. 
the cover and the upper part of the cylinder are concerned. It can play a significant part, however, if the gas volume shown in Fig. 1 were made available to accommodate core expansion.

Three runs were made with the ICECO model using different HCDA energies in the core. The first one, considered to be the reference case, had a source term equivalent to $2720 \mathrm{MW}-\mathrm{s}$, based on expansion of the fuel vapor to $1 \mathrm{~atm}$. This same source was used in an Argonne National Laboratory (ANL) study of pool-type reactors to evaluate the energy absorption capability of the stainless-steel sodium vessels comprising the primary containment for systems included in the pool study report. ${ }^{4}$ The pressure-volume relationship is shown in Fig. 2, which was reproduced from this reference. Here, $V_{F}$ is the final volume and $V$ is the current volume of the core. For the other two runs, called cases A and B, the pressures were doubled and quadrupled, respectively, with everything else being the same. The energy content associated with case A was $5440 \mathrm{MW}-\mathrm{s}$ and that associated with case B was $10880 \mathrm{MW}$-s. Histories of the pressures for these three runs were extended beyond the time of slug impact and were stored on permanent record for subsequent use with the PCRV model.

The reinforced biological shielding (or the PCRV) was modeled by the code DYNAPCON. In this version of the code, concrete is represented by a linearly elastic material where the cracking criterion is based on maximum stress; aggregate interlock is also approximated in a simplified manner. The components of the simplified axisymmetric PCRV model, together with the description of the analytical model, are shown in Fig. 3. The material properties used for modeling are given in Table I, while the equivalent prestressing values are listed in Table II. The plug was assumed to be a composite structure and to be attached to the general body of the PCRV at the

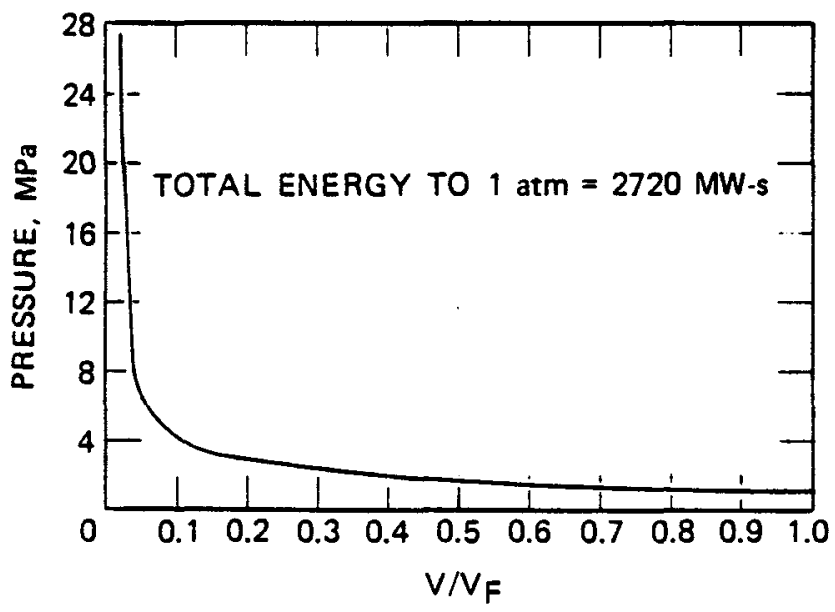

Fig. 2. Pressure-volume relationship for the reference case. upper right corner (one node only). No cracking was permitted in the plug.

The PCRV analytical model is first prepared for internal loading by prestressing it to the specifications given in Table II. This is accomplished by the dynamic relaxation procedure, ${ }^{1}$ where only elastic material behavior is considered and concrete cracking is not allowed. The plug does not participate in this prestressing operation. The PCRV model is retained as a permanent record, which becomes the initial state of the model before the internal loading from an HCDA is applied.

Before calculating the response of the PCRV due to internal dynamic loading, we first join the plug to the general reinforced/prestressed structure. Then the combined model of the structure is subjected to the previously derived pressure history. Here, cracking is permitted, according to the strain-rate dependence described in Ref. 1. The strain-rate dependence of reinforcing steel is also taken into account. Viscous

TABLE I

Material Properties Used in the PCRV Model

\begin{tabular}{|ll|}
\hline Concrete & \\
Compressive strength & $51.7 \mathrm{MPa}$ \\
Tensile strength & $3.58 \mathrm{MPa}$ \\
Elastic modulus & $33 \mathrm{GPa}$ \\
Poisson's ratio & 0.18 \\
Density & $2440 \mathrm{~kg} / \mathrm{m}^{3}$ \\
Prestressing tendons & \\
Yield strength & $1520 \mathrm{MPa}$ \\
Elastic modulus & $200 \mathrm{GPa}$ \\
Reinforcement & \\
Yield point & $400 \mathrm{MPa}$ \\
Elastic modulus & $200 \mathrm{GPa}$ \\
Plug material & \\
Elastic modulus & $50 \mathrm{GPa}$ \\
Poisson's ratio & 0.3 \\
Density & $4000 \mathrm{~kg} / \mathrm{m}^{3}$ \\
\hline
\end{tabular}

TABLE, II

Equivalent Prestressing of PCRV Model

\begin{tabular}{|l|c|c|l|}
\hline \multirow{2}{*}{ Location } & \multicolumn{3}{|c|}{ Type of Prestressing } \\
\cline { 2 - 4 } & Radial & Axial & Circumferential \\
\hline Bottom slab & $F=26.3 \mathrm{MN} / \mathrm{m}$ & --- & $p=3.87 \mathrm{MPa}$ \\
& $h=3.18 \mathrm{~cm}$ & --- & $h=6.7 \mathrm{~cm}$ \\
Top slab & $F=26.3 \mathrm{MN} / \mathrm{m}$ & --- & $p=7.75 \mathrm{MPa}$ \\
& $h=3.18 \mathrm{~cm}$ & --- & $h=13.41 \mathrm{~cm}$ \\
Cylinder & --- & $F=9.72 \mathrm{MN} / \mathrm{m}$ & $p=3.87 \mathrm{MPa}$ \\
& --- & $h=1.17 \mathrm{~cm}$ & $h=6.7 \mathrm{~cm}$ \\
\hline
\end{tabular}

NUCLEAR TECHNOLOGY VOL. 51 MID.DEC. 1980 
Seidensticker et al. INCREASING CAPABILITIES BY PRESTRESSED CONCRETE

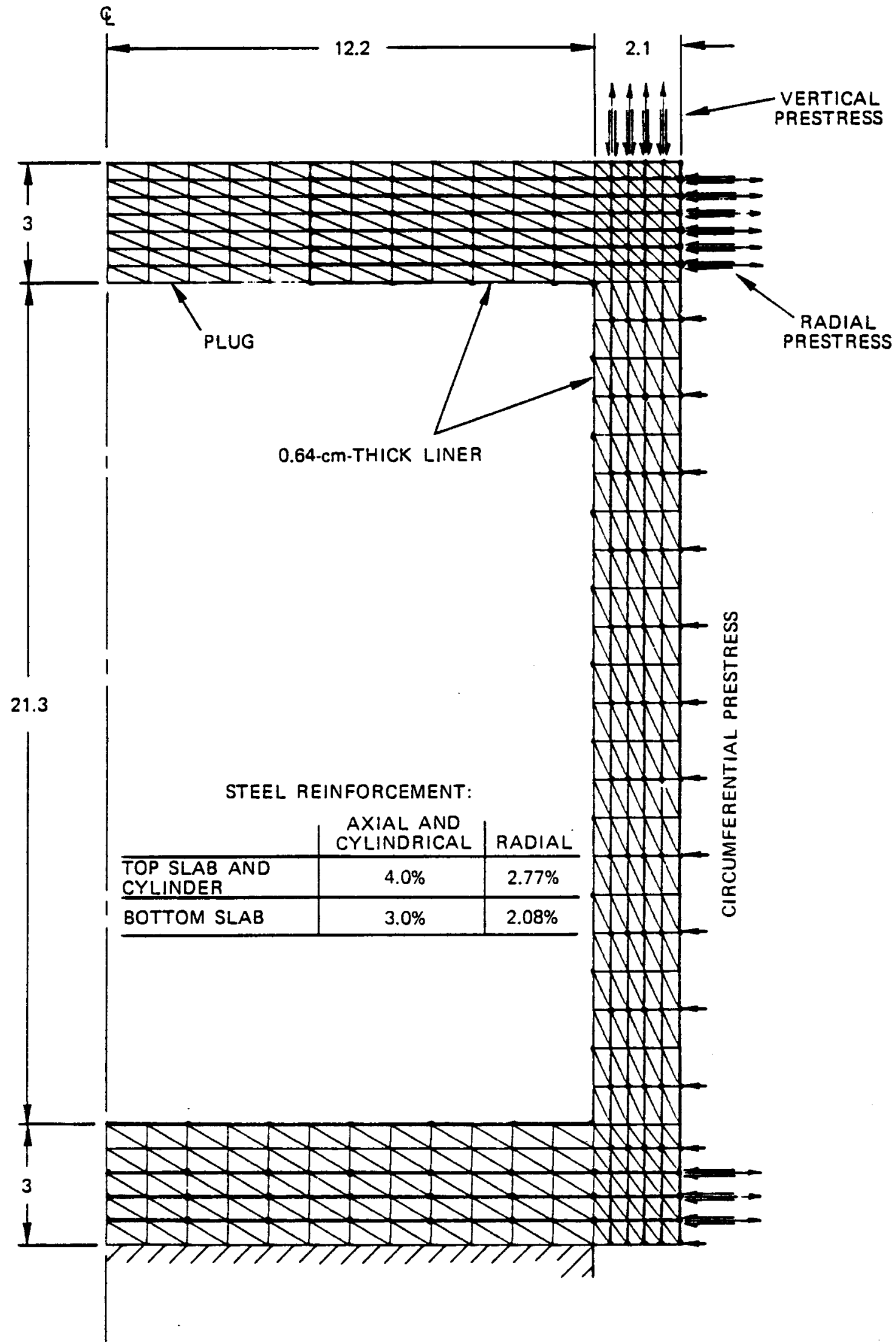

Fig. 3. Discretization and prestressing of the PCRV model. 
damping in the numerical simulations is used to the minimum; however, it is increased when extensive cracking occurs, which makes the continuation of the solution difficult.

Note that the objective of this analytical solution was to monitor the behavior of the steel tendons, the main load-carrying members of the structure. This objective necessitated carrying the solution through the largest pressure peaks of the loading so that the tendons would be stressed to their maximum values. It turned out that solutions were necessary far beyond the point after extensive concrete cracking had taken place. These situations necessitated increases in viscous damping and the reduction of the time step.

\section{DISCUSSION OF RESULTS}

The progress of the simulation of cracking through the walls of the PCRV model is quite interesting. Figures 4 and 5 depict the sequence of cracking for cases $A$ and $B$, respectively. Note that the plug is not allowed to undergo any cracking; it serves solely as a member transmitting load to the main PCRV body.

It is observed that for case A, extensive cracking is first initiated with the slug impact, which begins at $0.0615 \mathrm{~s}$. After the impact, radial cracks propagate also through the cylinder walls starting from the top of the vessel. For case B, circumferential stresses in the vessel cause radial cracks below the core before the slug impact starting at 0.0434 s. Slug impact causes circumferential cracks at the top cover and the top of the cylinder wall. Additional radial cracks appear in the cylinder wall after slug impact. Because the cracking sequences are different for the two cases, it can be seen that the maximum strains and stresses in the PCRV model vary with location and time. The location of maximum radial displacement of the cylindrical wall, for example, would depend on the loading case considered.

For all of the PCRV model runs, the strains of the tendons were monitored. A continuous record of strain values for the top and bottom layer of the top slab and the inner and outer layers of the vertical wall tendons were monitored. In addition, the circumferential strain of the simulated wire wrap midway between the top and bottom slabs was recorded. The absolute maximum recorded strain values for the radial tendons in the top slab, the axial tendons of the cylindrical wall, and the circumferential prestressed wire windings were determined and are plotted in Fig. 6. Combined with the respective maximum strain values for all the three runs, the curves provide us information on the trend of maximum strain as a function of the energy content of the HCDA. There appears to be a certain degree of uncertainty regarding the shape of the curves, like that of the circumferential wire strain at the midpoint of the cylindrical wall. It is not clear at this point, especially keeping in mind the different cracking sequences in Figs. 4 and 5, that an inflection in the relationship is all that unreasonable. More detailed studies may reveal the answer. The fact that the maximum strain values are acceptable is, however, the significant result of the study. For the imaginary HCDA source of $10880 \mathrm{MW}$-s (case B), the maximum strain is $2.3 \%$. The maximum ultimate static strain values for these tendons quoted in the literature range from 3 to $6 \%$. For dynamic conditions, as the PCRV modeling, this range would probably be higher.

To put the range of HCDA energies in perspective, we should refer to some typical values used in present designs. The maximum HCDA reference case for the Clinch River Breeder Reactor (CRBR) is $661 \mathrm{MW}-\mathrm{s}$ (Ref. 5), while that for the French Super-Phenix is $800 \mathrm{MW}$-s (Ref. 6). For such energy magnitudes, the maximum strains in the tendons from Fig. 6 would hardly be noticeable. It appears that under the most conservative conditions, the HCDA energy could easily be increased to $13000 \mathrm{MW}-\mathrm{s}$ to reach a maximum strain of $3 \%$ in the tendons. This corresponds to more than 16 times the HCDA source used for Super-Phenix.

Note that although the prestressing steel cables are not taxed to their ultimate capacity, cracking in the PCRV can be quite extensive, both in the extent of cracking and the crack opening sizes. Failure of the liner of the vessel thus becomes the object of interest as far as leak-tightness is concerned. This must be kept in mind in safety evaluations of the PCRV.

\section{CONCLUSIONS}

Preliminary calculations, based on rather conservative assumptions, indicate very large energy absorption potential using a PCRV for LMFBR primary containment. This potential is achieved by the introduction of large amounts of prestressing steel, both tendons and wound-wire, and large quantities of mild steel reinforcement into that physical space already devoted to concrete biological shield used in a typical pool-type LMFBR. The maximum steel tendon strains at any point are $2.3 \%$ for an energy source level of $10880 \mathrm{MW}$-s. This energy source of $10880 \mathrm{MW}-\mathrm{s}$ is $\sim 16.5$ times larger than the maximum reference case of $660 \mathrm{MW}-\mathrm{s}$ for the CRBR, and $\sim 13.6$ times larger than the reference design basis of 800 MW-s for the French Super-Phenix.

Clearly, certain questions remain to be answered more fully before it can be stated that economic engineering feasibility has been firmly established. The constitutive equations for the concrete must be developed further to include an improved understanding of the strain-rate dependence of the concrete 
Seidensticker et al. INCREASING CAPABILITIES BY PRESTRESSED CONCRETE

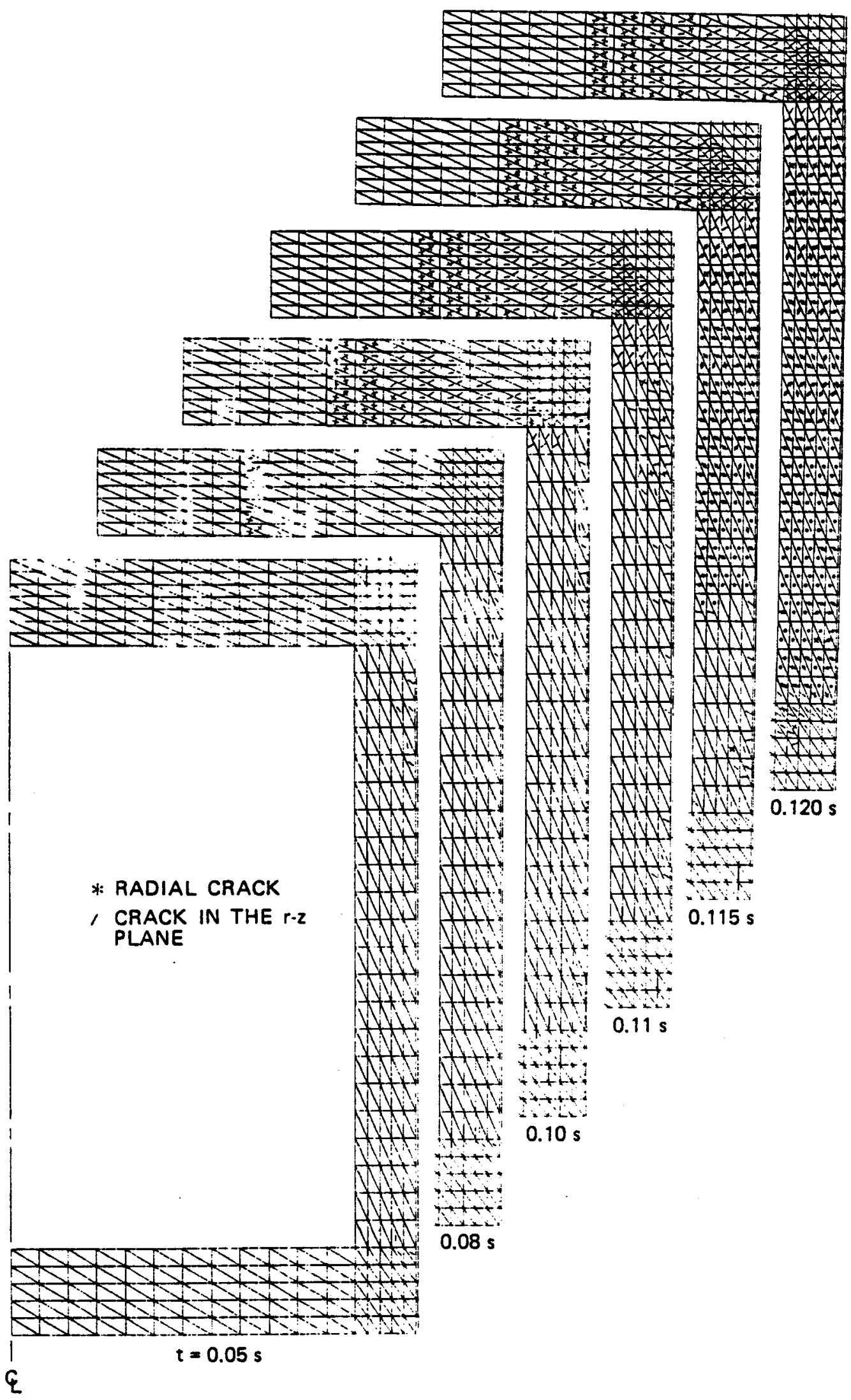

Fig. 4. Cracking sequence of PCRV model under case A loading. 




Fig. 5. Cracking sequence of PCRV model under case B loading. 


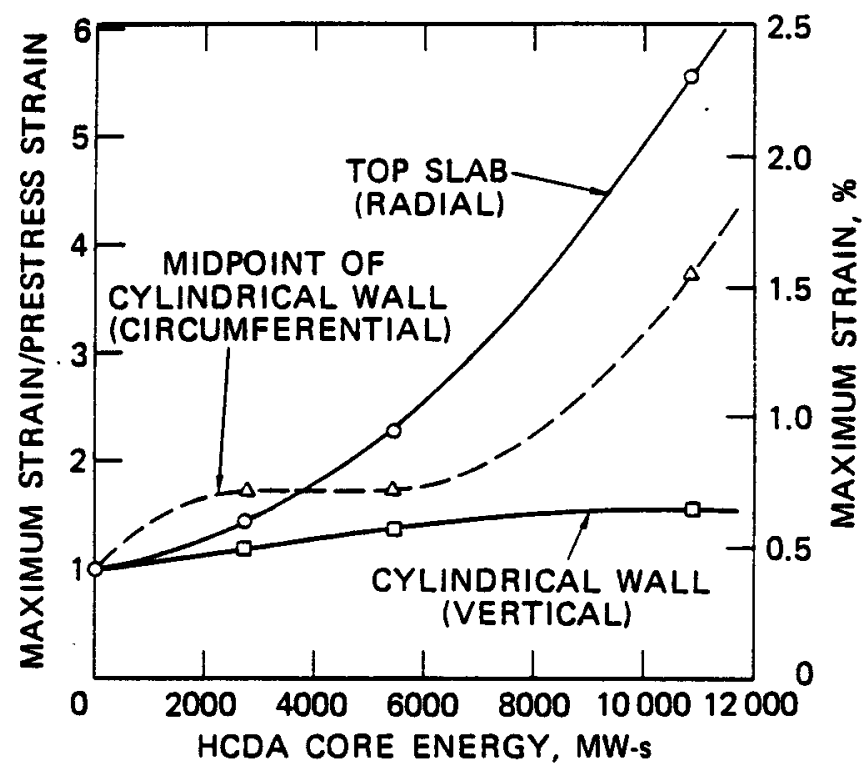

Fig. 6. Variation of maximum strain in prestressing tendon with HCDA energy content.

behavior. The design configuration used in this paper is admittedly greatly simplified, particularly with regard to the details of the PCRV liner and insulation of the liner and concrete. An analysis must be made assuming a flexible core barrel versus a rigid one. In spite of these limitations, however, preliminary feasibility seems assured. Clearly, very large energy absorption capability is achievable with reasonable amounts of prestressing and mild steel reinforcements. Coupling this with the well-established safe behavior in failure modes for PCRVs seems to provide strong incentives for carrying through the remaining work to establish a sound engineering basis for this concept.

This paper concerns the ultimate strength capacity of the PCRV. Leak-tightness of the PCRV, can, however, be of equal importance to the safety of the LMFBR design. The safety aspect of PCRV, involving fine points of concrete cracking as well as the degradation of concrete under severe environmental conditions, will be the subject of subsequent studies.

\section{ACKNOWLEDGMENTS}

The authors acknowledge the encouragement and advice of S. H. Fistedis who formulated the concept of PCRV for primary containment and initiated the original work in this area. We are indebted to individual members of the Engineering Mechanics Program for valuable suggestions during the study and in reviewing the paper.

The work reported here was performed in the Engineering Mechanics Program of the Reactor Analysis and Safety Division at ANL, under the sponsorship of the U.S. Department of Energy.

\section{REFERENCES}

1. A. H. MARCHERTAS and T. B. BELYTSCHKO, "Transient Analysis of a PCRV for LMFBR Primary Containment," Nucl. Technol, 51, 433 (1980).

2. C. Y. WANG, "ICECO-An Implicit Eulerian Method for Calculating Fluid Transients in Fast-Reactor Containment," ANL-75.81, Argonne National Laboratory (Dec. 1975).

3. A. H. MARCHERTAS et al., "Analysis and Application of Prestressed Concrete Reactor Vessels for LMFBR Containment," Nucl. Eng. Des., 49, 1-2 (1978).

4. A. AMOROSI et al., "An Overview of Pool-Type LMFBRs: General Characteristics," ANL-76-61, Argonne National Laboratory (May 1976).

5. C. M. ROMANDER and D. J. CAGLIOSTRO, "Structural Response of $1 / 20$-Scale Models of the Clinch River Breeder Reactor to a Simulated Hypothetical Core Disruptive Accident," SRI International Technical Report 4 to the U.S. Department of Energy (Oct. 1978).

6. H. NOËL, et al., "The Containment of the Creys-Malville Plant," 4th Int. Conf. Structural Mechanics in Reactor Technology, San Francisco, California, August 15-19, 1977, Paper J-1/4 (1977). 


\section{INCREASING PRIMARY CONTAINMENT CAPABILITIES OF LIQUID-METAL FAST BREEDER REACTOR PLANTS BY THE USE OF PRESTRESSED CONCRETE}

Ralph W. Seidenstick (top) (BS, civil engineering, Illinois Institute of Technolozy, 1955; MBA, University of Chicago, 1973) is a research engineer in the Reactor Analysis and Safety Division at Argonne National Laboratory (ANL). His current interest involves the use of prestressed concrete structures for both primary and secondary containment for liquid-metal fast breeder reactor plants. He is active in the American Society of Civil Engineers (ASCE) committees on nuclear structures and has worked on the original ACI committee that developed code requirements for muctear concrete containment structures. Algirdas H. Marcher (center) (BS, mechanical engineering, University of Illinois, 1956; MS, theoretical and applied mechanics, University of Illinois, 1957; $\mathrm{PhD}$, applied mechanics, University of Nebrasto, 1963) has been involved in design, stress analysis, and mathematical modeling of structural problems at ANL since 1957. Recently, he has been developing the DYNAPCON code, which is intended for analytical modeling of prestressed and rinforced concrete structures under transient loading. Z P. Bažant (bottom) (civil engineer degree, Technical University, Prague, 1960; PhD, Czechoslovak Academy of Sciences, 1963 has been on the faculty of Northwestern University since 1969 and became a professor in 1973. He has also served as coordimtor for the Structural Engineering Program. He served as chriman of the ASCE Engineering Mechanics Division Committee on Properties of Materials and is a member of several editorial boards. For his research on inelastic behavior of concrete as well as stability and fracture, he received from ASCE the Huber Research Prize (1976) and the T. Y. Lin Award (1977). During 1978 and 1979, he heid a Guggenheim Fellowship and he was recipient of the 1975 Medal from RILEM, Paris.
Ralph W. Seidensticker Algirdas H. Marchertas Zdenëk P. Bažant

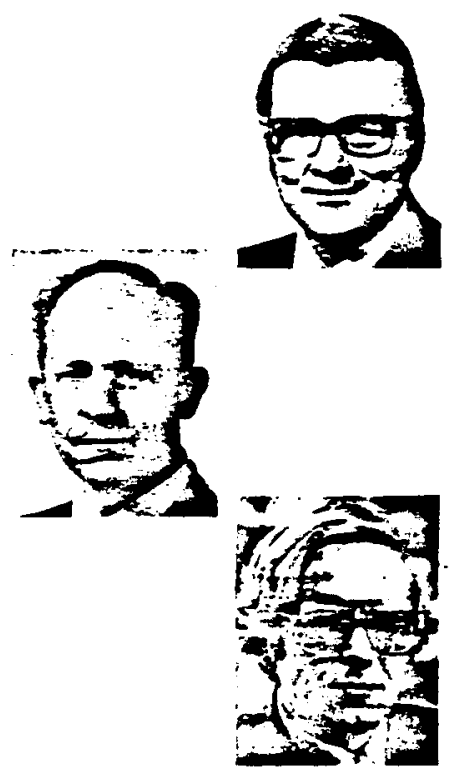

